\title{
Climate change social marketing on internet: review of interactivity to promote environmental sustainability
}

\author{
Vincent Didiek Wiet Aryanto ${ }^{1,{ }^{*}}$ and Yudith Vega Paramitadevi ${ }^{2}$ \\ ${ }^{1}$ Department of Management, Faculty of Economics and Business, Universitas Dian Nuswantoro \\ Semarang \\ ${ }^{2}$ Department of Environmental Engineering, Vocation School, Institut Pertanian Bogor
}

\begin{abstract}
This study aims at reviewing the interactivity of three prominent climate change website in Indonesia myplanet.care; Walhi (friend of Earth Indonesia) and Greenpeace Indonesia. Experimental research on interactivity was undertaken by involving 16 participants from one prominent private university and one prominent public university in Semarang. Reviewing process was done by situating the participants in one place to thoroghly investigate the three websites. The findings refer to 3 elements of interactivity namely social website interactivity, accessibility and navigation capability.
\end{abstract}

\section{Introduction}

To date, climate change is becoming a recent issue globally [1]. IPCC (inter-governmental panel on climate change) is an international body to facilitate and organize the occurence of climate change and its risk. Cohorts of environmental scientists contend that climate change is caused by human actions (anthropogenic). In 1997 leaders around the world made a consensus to arrange collective endeavors to alleviate climate change in Kyoto Protocol 1997.

Climate change so far, is not a daunting concern in Indonesia; where there are many urging issues encountered the country such as poverty and economic problems. Dated back to 1989 when Indonesia has joined the consensus under the United Nations General Assembly's inter-governmental negotiating committee for a framework convention on climate change. Indonesia endorsed Kyoto Protocol in 1998 but it did not approve until 2004. The opponent of climate change related with coal mining industry which argued that Climate change ratification will dwindle the economic performance of the country [2].

The unawareness on the veracity of the climate change is not only for the Indonesians but also for the American. They perceive that climate change is less serious issue to the detrimental of their life and environment [3]. There is a gap of knowledge between environment scientists and public on the reality of climate change and its risk to the

\footnotetext{
* Corresponding author: vincentaryanto@dsn.dinus.ac.id
} 
environment such as extinction of coral reefs, whether and harvest disruption and other occurrences that lower the quality of life and the environment [4].

\subsection{Social marketing}

Social marketing is a public campaign aiming at influencing and facilitating individual through marketing intervention. The design of social marketing program should understand in-depth of the target audiences. The social marketing intervention could be in terms of public education, public campaign through social media, internet, and mass media. However, programs and campaigns that try to educate the public are often perceived to be patriarchal since public sometimes is regarded as subordinate. Effective communication between senders and receivers are not limited on the messages but also the relationship development between two parties [4 - 6] support the previous understanding of social marketing as a systematic function of marketing concept and technique to attain particular behavioral objectives.

\subsection{Social website interactivity}

Interactivity can be defined as dialogue that happens as a two-way communication between individual to computer or internet. Interactivity also means as a method of communication that leads to the wider range of relations [7]. Social website interactivity represents to the action a user carries out surfing when navigate a website. [4] adds that websites are recognized as an effective media interactions network because of their relatively low cost, direct and manageable characteristics. In this regard, social website interactivity develops strong mutual relations between systems and users. The potential influence of website interactivity on public's behavioral intentions might not happen except website users like impressive public experiences [8]. In this regard, the there is a need to investigate how interactivity affects behavioral intention on climate change in this paper. We propose three model of website interactivity: 1. Human-interface relationship, or the experience of the internet (online) environment to human particularly in gaining the online social marketing information; 2. Accessibility refers to public's capability to access any social marketing information immediately without no delay, connectedness, quick response time and responsiveness and real time feedback. 3. Navigation is described as public's capability to look for the preferred information. Statement of the problems can be elaborated as follows:

1. How do the websites of climate change social marketing accommodate the humaninterface relationship?

2. How do the websites of climate change social marketing accommodate the accessibility of the public?

3. How do the websites of climate change social marketing facilitate the navigation of the public?

\section{Methods}

The sample list of websites that their content related to social marketing on climate change is as follows:

1. My planet.care (https://myplanet.care/id/) ---- W1

2. Friend of Earth Indonesia (WALHI = Wahana Lingkungan Hidup Indonesia) (https://www.foei.org/member-groups/asia-pacific/indonesia) ---- W2 
3. Greenpeace Indonesia (http://www.greenpeace.org/seasia/id/campaigns/perubahan-iklim-global/) ---- W3

Three prominent websites that promote social marketing on climate change were chosen to be the research objects. The primary aim of this research was to examine the websites interactivity during the month of May 2018. Participants of this research were 8 graduate students of prominent private university in Semarang which was Dian Nuswantoro University and 8 students of Diponegoro University that represented a prominent public university. Therefore, the total participants were 16 students of graduate school. In May 2018 they were gathered in one class from both universities to examine the interactivity of three websites on climate change. They were given to examine those three websites in terms of human-interface relationship, accessibility, and navigation of the information. The interactivity examinations were conducted in two steps. First they were given time to explore thoroughly the websites to acquaint their interactivity. Second, the student participants were given time to contact, ask, and inquire to the website administrators to get to know their realtime responsiveness (Table 1).

Table 1. Profile of the participants.

\begin{tabular}{|l|l|l|l|}
\hline No & Participants & Number & Frequency (\%) \\
\hline 1 & Graduate school Dian Nuswantoro University & 8 & 50 \\
\hline 2 & Graduate school Diponegoro University & 8 & 50 \\
\hline 3 & Male students & 10 & 63 \\
\hline 4 & Female students & 6 & 37 \\
\hline & & & \\
\hline
\end{tabular}

\section{Finding and discussion}

All the 16 student participants (100\%) agree that the availability of information on climate change are well-inform. The participants believe that the provided information will solve the gap between public who knows and those who do not know (knowledge digital divide). The public campaign in the form of social marketing on climate change of three websites is supposed to bridge the knowledge divide on climate change. The attractiveness of pictures and videos may give the deep information on climate change. These findings are supported by $[9,10]$. The human-interface interaction deals with relationships and the experiences of the virtual environment. The higher degree of interactivity is attained through websites content composed of massages, information, news, dialogue, pictures, videos, however, 40 $\%$ of the participants do not surf the internet unless there is no assignment form their professors. This tells us that the information on climate change is not a priority of the participants's favorite. Most of the participants (90\%) recognize the sustainability of the climate change program in soliciting the public donation. The $\mathrm{W} 1$ does not solicit the donation, since it is funded by the Ministry of Research and Technology. The public participation in terms of donation is considered as public awareness and active involvement in mitigating the climate change disruption.

The accessibility of three websites are examined by the participants (100\%) as accessible in terms of speed, quick response, no-delay, fast connection, real-time feedback. $80 \%$ of the participants contend that $\mathrm{W} 1$ is the best in terms of interactivity since this website utilizes the social media to interact with its public. The news and information update are a cumpulsory in the participants standpoint (60\%) and they choose W2 and the rest (40\%) choose W3 as the most accessible website. The navigation capability to find out the information availability, the disired knowledge on climate change and the navigation 
capability can be useful for mapping the behavioral intention of the public who seeks information on climate change.

Table 2. Description of participant's option.

\begin{tabular}{|l|l|l|l|l|}
\hline No & Description & Favorable & Unfavorable & $\%$ \\
\hline 1 & Websites inform the respondents on climate change & 16 & - & 100 \\
\hline 2 & Surfing on environment-friendly websites & 6 & 10 & 40 \\
\hline 3 & W1, W2, W3 solicit donation for program's viability & 14 & 2 & 90 \\
\hline 4 & W1 is the best website in terms of interactivity & 13 & 3 & 80 \\
\hline 5 & W2 is the best news and information update & 10 & - & 60 \\
\hline 6 & W3 is the most accessible website & 6 & - & 40 \\
\hline
\end{tabular}

This article has limitation that the participants are very limited in number and mostly those students who are in average knowledgable about climate change and global warming. Experimental research on experiencing to surf and investigate climate change websites can be the best practices for disseminating and enhancing views the public on climate change. The behavioral intention will be influenced by narrowing the gap of digital knowledge on climate change as also supported by [6]. Furthermore, [11] contend that pro-environmental behavior can be promoted through various digital media campaigns such as website, social media, and also limited treatment in class teaching.

\section{Acknowledgements}

We express our sincere gratitude to the reviewers to improve this article and Ministry of Research and Technology, Directorate of Higher Learning for supporting this research under the scheme of PKLN-DIKTI's research grant.

\section{References}

1. M. Boykoff, Transaction of the Institute of British Geographers 32, 477-489 (2007)

2. M.J. Green., A. Freeman, A. Public Perception on Climate Change in Asia (2010)

3. M.C., Nisbet, T. Myers, Public Opinion Quatterly 71, 3, 444-470 (2007)

4. C.H. Botan, J. Jun, Y. Hu, C. Roser-Renouf, Leiserowitz, Co-creation of Meaning in Environmental Communication (2010)

5. C.H. Botan, M. Taylor, Journal of Communication 54, 645-661 (2006)

6. A Corner, A. Randall, Global Climate Change 21, 1005-1014 (2011)

7. B. Florenthal, A. Shoham, Journal of Service Marketing 24, 1, 29-41 (2011)

8. L. Brennan, M.L. Fry, Previte, Australasian Marketing Journal (2015)

9. T.R., Morueta, J.I.A, Gomez, A.H. Gomez, Technology in Society (2013)

10. V.D.W. Aryanto, Y. Wismantoro, K. Widyatmoko, International Journal of e-Business Research 14, 1, 21-36. (2018)

11. R. Obaldiston, J.P. Schott, Environmental and Behavioral Science: Meta-Analysis of ProEnvironmental Behavior Experiments 44, 20, 207-299 (2012) 